\title{
Fakoemülsifikasyon Cerrahisinde Arka Kapsül Rüptürü ve Görsel Sonuçlara Etki eden Faktörler
}

\author{
Posterior Capsule Rupture in Phacoemulsification Surgery and \\ Factors Affecting Visual Outcomes \\ Kübra Özata Gündoğdu, Emine Doğan, Erkan Çelik, Gürsoy Alagöz \\ Sakarya Ĕ̆itim Ve Araştırma Hastanesi Göz Hastalıkları Kliniği, Sakarya

Yazışma Adresi / Correspondence:
Kübra Özata Güindoğdu
Sakarya Üniversitesi Eğitim ve Araştırma Hastanesi Korucuk Kampüs Göz Kliniği, Sakary $77 \quad$ E-mail : kubraoz78@hotmail.com
T: +90 505 9407477 Kabul Tarihi / Accepte: 01.11.2021
Geliş Tarihi / Received : 12.04.2021
Orcid :
Kübra Özata Gündoğdu https://orcid.org/0000-0001-7144-6235
Emine Doğan https://orcid.org/0000-0002-6505-3328
Erkan Çelik https://orcid.org/0000-0002-8681-7868
Gürsoy Alagöz https://orcid.org/0000-0002-7614-5690
( Sakarya Tip Dergisi / Sakarya Med J 2021, 11(4):836-842) DoI: 10.31832/smj.909194

\footnotetext{
öz

Amaç Katarakt cerrahisi sırasında arka kapsül rüptürü gelişen olgularda klinik sonuçların ve görsel sonuçlara etki eden faktörlerinin değerlendirilmesidir.

Yöntem ve Katarakt cerrahisi sırasında arka kapsül rüptürü gelişen 80 hastanın kayıtları retrospektif olarak incelendi. Hastalar postoperatif 3. ay düzeltilmiş en iyi görme keskinliğine

Gereçler göre 2 gruba ayrıldı; düzeltilmiş en iyi görme keskinliği $\leq 0,5$ olanlar Grup 1, >0,5 olanlar Grup 2 olarak sinıflandırıldı. Gruplarda yaş, cinsiyet, operatörün tecrübesi, katarakt tipi, oküler ek hastalıkların mevcudiyeti, pupillanın dilatasyonu, arka kapsül rüptürü gelişim aşaması, intraoküler lens implantasyon zamanı ve yeri, postoperatif komplikasyonlar gibi faktörler incelendi ve postoperatif görme keskinliğine etkileri analiz edildi.

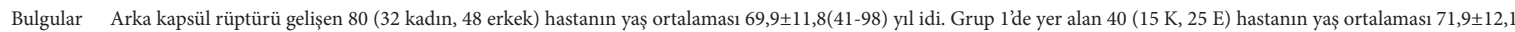
iken; Grup 2'de yer alan 40 (17 K, 23 E) hastanı 67,9 $\pm 11,4$ yl idi ve gruplarda yaş ve cinsiyet açısından fark yoktu (p:0,205, p:0,819). Grup l'de matur katarakt oranı anlamlı olarak yüksekti (p:0,018). Gruplar arasında pupilla dilatasyon durumu benzerdi (p:0,728). Gruplar arasında sistemik hastalıklar açısından farkllık yoktu. Grup l'de oküler hastalık oranı daha yüksek bulunmustu (p:0,001). Gruplar arasında cerrahın tecrübesi açısından farklllk saptanmadı (p:0,762). Arka kapsül rüptürü; Grup l'de en sik fakoemülsifikasyon aşamasında, Grup 2'de en sık irrigasyon-aspirasyon aşamasında gelişmişți. Grup 1'de aynı seansta intraoküler lens implantasyonu yapılamayp sekonder olarak implantasyon yapılan hasta sayısı daha fazlaydı (p:0,020). Postoperatif komplikasyon oranları iki grup arasında benzer bulunmuștu.

Sonuç Fakoemülsifikasyon cerrahisi sırasında arka kapsül rüptürü gelişen hastaların görme düzeyleri; yoğun kataraktı, ek oküler hastalılkları ve sekonder göz iç̣ lens implantasyonu yapilmış olanlarda daha kötüydü.

Anahtar

Kelimeler

Fakoemülsifikasyon; katarakt cerrahisi komplikasyon; arka kapsül rüptürü

Abstract

Introduction Evaluation of clinical outcomes and factors affecting visual outcomes in patients with posterior capsule rupture during cataract surgery.

Materials The records of 80 patients who developed posterior capsule rupture during cataract surgery were analyzed retrospectively. The patients were divided into 2 groups according to and Methods their best corrected visual acuity at postoperative 3rd month. Those with best corrected visual acuity $\leq 0.5$ were classified as Group 1 and those with $>0.5$ as Group 2. Factor such as age, gender, operator's experience, cataract type, presence of ocular comorbidity, pupil dilatation, development stage of posterior capsule rupture, time and location of intraocular lens implantation, postoperative complications were analyzed in the groups and their effects on postoperative visual acuity were analyzed.

Results The mean age of 80 patients ( 32 females, 48 males) who developed posterior capsule rupture was $69.9 \pm 11.8$ (41-98) years. The mean age of 40 (15 F, $25 \mathrm{M}$ ) patients in Group 1 was $71.9 \pm 12.1$ years; in Group 2, which included $40(17$ F, $23 \mathrm{M})$ patients, it was $67.9 \pm 11.4$ years and there was no difference in age and gender in the groups ( $p: 0.205$, p: 0.819). The rate of mature cataract was significantly higher in Group 1 ( $p: 0.018$ ). Pupil dilatation status was similar between the groups ( $p: 0.728)$. There was no difference in systemic diseases between the groups. Additional ocular disease rate was higher in Group 1 ( $p: 0.001)$. There was no difference between the groups in terms of the experience of the surgeon (p: 0.762). Posterior capsule rupture; it was most frequently in the phacoemulsification stage in Group 1, and the most frequently in the irrigation-aspiration stage in Group 2. The patients who intraocular lens could not be implanted in the first surgery were found to be higher in Group 1 (p: 0.020). Postoperative complication rates were similar between the two groups.

Conclusion Visual outcomes of patients who developed posterior capsule rupture during phacoemulsification surgery; it was worse in those with dense cataracts, additional ocular diseases and secondary intraocular lens implantation.

Keywords Phacoemulsification; complications of cataract surgery; posterior capsule rupture
} 


\section{GIIRIŞ}

Kelman ile 1967 yılında uygulanmaya başlayan fakoemülsifikasyon ile katarakt cerrahisi günümüzde standart bir cerrahi teknik haline gelmiştir. ${ }^{1}$

Fakoemülsifikasyon cerrahisinde ultrasonik titreşimler ile nukleus emülsifiye edilip aspirasyon ile temizlenmektedir. Probun korneal kesi yerinden ön kamaraya girmesi ile kapalı bir alanda işlem gerçekleşmektedir. Modern bir teknik olmasına rağmen intraoperatif ve postoperatif komplikasyonlar oluşabilmektedir. Cerrahi sırasında arka kapsül bütünlüğü intraoperatif komplikasyonlar açısından önemlidir. ${ }^{2}$ Arka kapsül rüptürü (AKR); cerrahinin hidrodiseksiyon, fakoemülsifikasyon, irrigasyon-aspirasyon veya intraoküler lens (İOL) yerleştirilmesi aşamasında ortaya çıkabilir. ${ }^{3}$ AKR oluştuğu zaman cerrahinin süresi uzamakta ve kistoid maküla ödemi, retina dekolmanı gibi komplikasyonlara sebep olabilmektedir. ${ }^{4}$

AKR için oküler ve sistemik risk faktörleri tanımlanmıştır. Çukur göz, dar palpebral fissür, yüksek miyopi, glokom, geçirilmiş pars plana vitrektomi gibi sebepler oküler risk faktörlerinden sayılırken; ciddi obezite, Marfan sendromu, diyabetes mellitus ve sistemik hipertansiyon ise sistemik risk faktörleri olarak saptanmıştır. ${ }^{3}$

$\mathrm{Bu}$ çalışmada amaç; fakoemülsifikasyon cerrahisi sırasında AKR gelişen vakaların görsel sonuçlarının değerlendirilmesi ve olası risk faktörlerinin saptanmasıdır.

\section{GEREÇ ve YÖNTEMLER}

Sakarya Üniversitesi Eğitim ve Araştırma Hastanesi Göz Kliniği’nde Ocak 2016- Ocak 2020 tarihleri arasında fakoemülsifikasyon cerrahisi sırasında AKR gelişen 113 hastanın 113 gözü dosya taraması yapılarak retrospektif olarak incelendi. Künt veya penetran travma hikayesi olan, trabekülektomi veya vitrektomi gibi geçirilmiş göz içi cerrahisi olan, intravitreal enjeksiyon yapılma öyküsü olan, preoperatif muayenede lens subluksasyonu olan 33 hasta çalışma dışı bırakıldı ve 80 hasta çalışmaya alındı.
Hastaların preoperatif Snellen eşeli ile düzeltilmiş en iyi görme keskinliği (DEİGK), Goldmann aplanasyon tonometrisi ile göz içi basıç̧ları (GİB), biyomikroskopik muayene ile kornea, pupilla ve kataraktın durumu değerlendirildi. Fundusu aydinlanan hastalarda detaylı fundus muayenesi, aydınlanmayan hastalarda ise B-mod ultrasonografi ile retinanın yatışık olup olmadığı değerlendirildi. Hastalara preoperatif dilatasyon amaciyla Tropikamid \%5 ve $\% 10$ 'luk fenilefrin HCL damla 5 dakika arayla üçer defa damlatıldı. Ameliyatlar farklı tecrübeye sahip cerrahlar tarafından lokal anestezi altında gerçekleştirildi. Fakoemülsifikasyon İnfiniti (Alcon Surgical ${ }^{\oplus}$ ) cihazıyla uygulandı. Kornea üst temporalden yapılan 2.8 mm'lik kesiden sonra ön kamaraya viskoelastik madde verilerek kontinu kurvilineer kapsüloreksis yapıldı. Hidrodiseksiyon-hidrodelineasyon işlemlerinden sonra fakoemülsifikasyon probu ile nükleus emülsifiye edildi. İrrigasyon-aspirasyon modu ile korteks temizliği yapıldı. AKR gelişme aşamasına göre cihaz değerleri değiştirilerek vitreus gelmişse ön vitrektomi ile kalan katarakt parçaları temizlendi. Cerrahın tercihine veya kalan nükleus parçasının büyüklüğüne göre kesi yeri genişletilerek loop ile çıkartılıp insizyon yeri sütüre edildikten sonra ön vitrektomi yapılarak korteks bakiyeleri temizlendi. Ön ve arka kapsül durumuna göre İOL kapsül içine veya sulkusa implante edildi. Yeterli kapsül desteği olmayanlara ise sekonder olarak skleral fiksasyonla İOL yerleştirildi.

Hastalar postoperatif 3.ay DEİGK $\leq$ 0,5 olanlar Grup 1, DEİGK > 0,5 olanlar Grup 2 olarak sinıflandirıldı. Gruplarda yaş, cinsiyet, operatörün tecrübesi, katarakt tipi, diyabetes mellitus (DM) ve hipertansiyon (HT) gibi sistemik hastalıkların varlığı, psödoeksfoliasyon (PSX), glokom, üveit gibi oküler hastalıkların varlığı, pupillanın dilatasyon durumu, AKR gelişim aşaması gibi faktörler incelendi ve iki grup arasında farklılık olup olmadığına bakıldı. Tanımlayıcı istatistikler için kategorik değişkenlerde sayı ve yüzde, sayısal değişkenlerde ise ortalama ve standart sapma kullanıldı. İstatistiksel testler için SPSS 21 (SPSS Inc., Chicago, IL, USA) programı kullanıldı. Grup- 
lar arası kategorik değişkenlerin karşılaştırılması amacıyla Ki kare testi ve veriler normal dağılmadığ 1 için non-parametrik test olan Mann Whitney-U testleri kullanıldı ve $p$ değeri 0,05 altı ise anlamlı olarak kabul edildi.

\section{BULGULAR}

Fakoemülsifikasyon cerrahisi sırasında AKR gelişen 80 hastanın 80 gözü çalışmaya alındı. Hastaların 32'si (\%40)

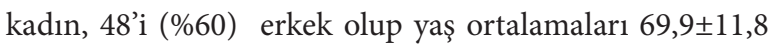
(41-98) yıl idi. Grup 1'de yer alan 40 hastanın 15'i kadın,

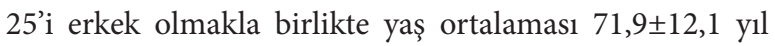
idi. Grup 2'de yer alan 40 hastanın 17'si kadın, 23'ü erkek olmakla birlikte yaş ortalaması $67,9 \pm 11,4$ yıl idi. Gruplarda yaş ve cinsiyet açısından fark saptanmadı (p:0,205, p:0,819).

Hastaların katarakt tiplerine göre ayrımı yapılırken matür ve nigra katarakt, matür katarakt olarak; nükleer, kortikal, ön kapsüler, arka kapsüler ve bunların kombinasyonları, immatür katarakt olarak değerlendirildi. Grup 1'de matür katarakt oranı anlamlı olarak yüksekti (p:0,018) (Tablo 1). Hastaların pupil dilatasyonu durumuna baktığımızda grup l'de 6 hastada (\%15) dilatasyon zayıf, 12 hastada (\%30) orta, 22 hastada (\%55) iyi iken; grup 2'de 4 hastada (\%10) zayıf, 11 hastada $(\% 27,5)$ orta, 25 hastada $(\% 62,5)$ iyi idi. Pupilla dilatasyonu açısından iki grup arasında istatistiksel olarak anlamlı fark yoktu (p:0,728).

Tablo 1: Fakoemülsifikasyon cerrahisi sırasında arka kapsül rüptürü gelişip postoperatif DEİGK $\leq 0,5$ ve DEİGK $>0,5$ olan hastaların katarakt tipi oranları

\begin{tabular}{|c|c|c|c|}
\hline $\begin{array}{l}\text { Katarakt } \\
\text { çeşidi }(n, \%)\end{array}$ & $\begin{array}{c}\text { Grup } 1 \\
(\text { DEİGK } \leq \\
0,5)\end{array}$ & $\begin{array}{c}\text { Grup } 2 \\
(\text { DEİGK > } \\
0,5)\end{array}$ & p değeri \\
\hline Matür & $14(\% 35)$ & $5(\% 12,5)$ & \multirow{2}{*}{0,018} \\
\hline İmmatür & $26(\% 65)$ & $35(\% 87,5)$ & \\
\hline
\end{tabular}

DM ve HT gibi sistemik hastalık açısından iki grup karşılaştırıldığında anlamlı farklılık saptanmadı (p:0,639, p:0,499) (Tablo 2).
Tablo 2: Fakoemülsifikasyon cerrahisi sırasında arka kapsül rüptürü gelişip postoperatif $\mathrm{DEI} G K \leq 0,5$ ve $\mathrm{DEIGGK}>0,5$ olan hastaların ek sistemik hastalık oranları

\begin{tabular}{|l|c|c|c|}
\hline $\begin{array}{l}\text { Sistemik } \\
\text { hastalık (n,\%) }\end{array}$ & $\begin{array}{c}\text { Grup 1 } \\
(\text { DEIGK } \leq \\
\mathbf{0 , 5})\end{array}$ & $\begin{array}{c}\text { Grup 2 } \\
(\text { DEIGK }> \\
\mathbf{0 , 5})\end{array}$ & p değeri \\
\hline DM & $15(\% 37,5)$ & $13(\% 32,5)$ & 0,680 \\
\hline HT & $17(\% 42,5)$ & $19(\% 47,5)$ & 0,720 \\
\hline
\end{tabular}

(DM: Diyabetes Mellitus, HT: Hipertansiyon, DEIGK: Düzeltilmiş en iyi görme keskinliği)

Gruplarda PSX, glokom, üveit, korneal nefelyon, senil makula dejenerasyonu (SMD), diyabetik retinopati (DRP), retinal ven tıkanıklığı (RVT), hipertansif retinopati (HTRP) gibi oküler ek hastalık varlığı incelendi. Grup l'de hastaların 25'inde (\% 62,5), Grup 2'de 9'unda (\%22,5) oküler ek hastalık mevcuttu ve aralarındaki fark anlamlıy$\mathrm{d}_{1}$ (p:0,001) (Tablo 3).

Tablo 3: Fakoemülsifikasyon cerrahisi sırasında arka kapsül rüptürü gelişip postoperatif DEİGK $\leq 0,5$ ve DEİGK $>0,5$ olan hastaların ek oküler hastalık oranları

\begin{tabular}{|l|c|c|}
\hline $\begin{array}{l}\text { Oküler Ek } \\
\text { Hastalı (n,\%) }\end{array}$ & $\begin{array}{c}\text { Grup 1 } \\
(\text { DEİGK } \leq \mathbf{0 , 5})\end{array}$ & $\begin{array}{c}\text { Grup 2 } \\
(\text { DEİGK > 0,5) }\end{array}$ \\
\hline SMD & $7(\% 17,5)$ & $1(\% 2,5)$ \\
\hline DRP & $11(\% 27,5)$ & $3(\% 7,5)$ \\
\hline RVT & $0(\% 0)$ & $2(\% 5)$ \\
\hline HTRP & $1(\% 2,5)$ & $0(\% 0)$ \\
\hline PSX & $4(\% 10)$ & $1(\% 2,5)$ \\
\hline Epiretinal membran & $3(\% 7,5)$ & $2(\% 5)$ \\
\hline Glokom & $5(\% 12,5)$ & $2(\% 5)$ \\
\hline Dejeneratif miyopi & $2(\% 5)$ & $1(\% 2,5)$ \\
\hline Korneal nefelyon & $2(\% 5)$ & $0(\% 0)$ \\
\hline $\begin{array}{l}\text { (SMD: senil makula dejenerasyonu, DRP: diyabetik retinopati, } \\
\text { RVT: retinal ven tıkanıklı̆̆, HTRP: hipertansif retinopati, PSX: } \\
\text { psödoeksfoliasyon, DEIGK: Düzeltilmiş en iyi görme keskinliği) }\end{array}$
\end{tabular}

Hastaların preoperatif görme düzeyleri ortalaması sırasıyla 0,07 ve 0,13 iken; göz içi basınçları ortalaması sırasıyla 15,7 ve 15,5 'ti ve iki grup arasında anlamlı farklılık yoktu ( $p>0,05)$. Postoperatif görme düzeyleri ortalaması sırasıyla 0,25 ve 0,75 iken; göz içi basınçları ortalaması sırasıyla 15,6 ve 15,15 idi (sırasiyla p:0,001, p:0,524). 
Grup 1'de 34 (\%85), Grup 2'de 33 (\%82,5) hastada operasyonu 100'ün üzerinde olgu deneyimi olan cerrahlar yapmıştı ve iki grup arasında cerrahın deneyimi açısında anlamlı farklılık saptanmadı (p:0.762).

AKR; Grup 1'de hastaların 25'inde (\%62,5) fakoemülsifikasyon aşamasında, 13'ünde (\%32,5) irrigasyon-aspirasyon aşamasında, 2'sinde (\%5) İOL yerleștirildikten sonra gelişirken; Grup 2'de hastaların 20'sinde (\%50) irrigasyon-aspirasyon aşamasında, 18'inde (\%45) fakoemülsifikasyon aşamasında, 2'sinde (\%5) İOL yerleștirildikten sonra gelişmişti. İki grup arasında AKR gelişim aşaması açısından anlamlı farklılık saptanmadı (p:0,267).

İOL implantasyon yeri açısından iki grup değerlendirildiğinde iki grup arasında anlamlı farklılık saptanmadı (Tablo 4). İOL implantasyon yerinden bağımsız katarakt cerrahisi ile aynı seansta veya sekonder olarak sınıfladığımızda; Grup 1'de $25(\% 62,5)$ hastaya aynı seansta, $15(\% 37,5)$ hastaya sekonder olarak İOL implantasyonu yapılmış iken; Grup 2’ de 35 (\%87,5) hastaya aynı seansta, 5 (\%12,5) hastaya sekonder olarak İOL implantantasyonu yapılmıştı. İki grup arasında anlamlı bir farklılık saptandı (p:0,02).

\begin{tabular}{|c|c|c|}
\hline $\begin{array}{l}\text { İOL implantasyonu } \\
(\mathbf{n}, \%)\end{array}$ & $\begin{array}{c}\text { Grup } 1 \\
(\mathrm{DEIGK} \leq 0,5)\end{array}$ & $\begin{array}{c}\text { Grup } 2 \\
(\text { DEİGK }>0,5)\end{array}$ \\
\hline Kapsüler kese & $2(\% 5)$ & $6(\% 15)$ \\
\hline Siliyer sulkus & $23(\% 57.5)$ & $29(\% 72.5)$ \\
\hline $\begin{array}{l}\text { Sekonder siliyer } \\
\text { sulkus }\end{array}$ & $6(\% 15)$ & $3(\% 7.5)$ \\
\hline $\begin{array}{l}\text { Sekonder skleral } \\
\text { fiksasyon }\end{array}$ & $9(\% 22.5)$ & $2(\% 5)$ \\
\hline \multicolumn{3}{|c|}{$\begin{array}{l}\text { (İOL: intraoküler lens, DEİGK: Düzeltilmiş en iyi görme keskin- } \\
\text { liği) }\end{array}$} \\
\hline
\end{tabular}

Bütün hastalarımızda AKR geliştikten sonra vitreus gelmiş olup ön vitrektomi uygulanmıştı. AKR gelişimi sonrası; Grup 1'de 8 (\%20) hastada Grup 2'de ise 2 (\%5) hastada nükleus drop gelişmişti. Drop gelişen olgular değerlendi- rildiğinde; Grup 1'de $5(\% 12,5)$ hasta vitreoretinal cerrahiye giderken, Grup 2'deki hastalarda vitredeki nükleus medikal tedavi ile rezorbe olmuş ve herhangi bir cerrahi girişim gerekmemiştir. Postoperatif kornea ödemi Grup l'de 8 (\%20), Grup 2'de $11(\% 27,5)$ hastada görülmüş olup, medikal tedavi ile gerilemiştir. Grup l'de postoperatif kistoid makula ödemi gelişen 4 (\%10) hastanın 2'sine Grup 2'de ise 2 (\%5) hastanın 1'ine intravitreal enjeksiyon uygulanmıştı. İki grupta da birer hastada İOL desantralizasyonu olup İOL repozisyonu yapılmıştı. Grup 1'de $1(\% 2,5)$ hastada retina dekolmanı gelişmişti. Gruplar arasında komplikasyon açısından anlamlı farklılık saptanmadı.

\section{TARTIŞMA}

Fakoemülsifikasyon, hızlı görsel sonuçlar ve az astigmat yapması nedeniyle katarakt cerrahisinde tercih edilen yöntem haline gelmiştir. Küçük insizyondan gerçekleştirilen cerrahi sayesinde suprakoroidal hemoraji riski çok azalmıştır. ${ }^{5}$

Fakoemülsifikasyon cerrahisi sırasında AKR meydana gelme olasılığını etkileyen risk faktörleri vardır. İleri yaş cerrahinin komplikasyon olma oranını artırmaktadır. Yaş ilerledikçe küçük pupilla, PSX varlığı, kataraktın daha sert olma durumu arttığından dolayı bu risk artıyor olabilir. İleri yaşta glokom ve senil makula dejenerasyonuna bağlı görme düzeyi etkileneceğinden katarakt cerrahisi sonrası görme keskinliği sonuçları düşük olabilir. ${ }^{6}$ Drolsum ve arkadaşlarının yaptığı çalışmada yaş, glokom, PSX, nükleer skleroz, yetersiz dilatasyon ve komplikasyon oranı açısından anlamlı korelasyon saptanmıştır. Çalışmamızda iki grup arasında yaş açısından bir fark bulunamamıştır.

Cerrahi sırasında perioperatif komplikasyonlar açısından cerrahın tecrübesi önemlidir. Bai ve arkadaşlarının yaptığ 1 bir çalışmada 100'ün altında ve üstünde vaka tecrübesi olan cerrahların yaptığı 1200 fakoemülsifikasyon ameliyatları karşılaştırılmıştır. AKR ve vitreus kaybı oranlar1 100'ün altında vaka tecrübesi olan cerrahların yaptığ1 ameliyatlarda yüksek bulunmuştur. İki grup arasında İOL 
implantasyonu oranları, postoperatif retina dekolmanı, nükleus drop sıklığı ve postoperatif görme düzeyi açısından iki grupta da anlamlı farklılık saptanmamıştır. ${ }^{8}$ Çalışmamızda iki grup arasında cerrahın tecrübesi açısından farklılık görülmemiştir. Yüzün üzerinde vaka tecrübesi olan cerrahların yaptığı ameliyatlarda 8 vakada nükleus drop olurken, vaka tecrübesi 100'ün altı olan cerrahların yaptığ1 ameliyatlarda 2 nükleus drop olmuştur. Tecrübeli cerrahların drop oranının fazla olmasının nedeni, preoperatif risk faktörü daha fazla olan hastaların bu cerrahlarca opere edilmesiyle ilişkili olabilir.

Karakurt ve ark'nın yaptığı çalışmada vakaların \%63,2'sinde nükleus emülsifikasyonu sırasında, \%29,5'inde irrigasyon-aspirasyon aşamasında arka kapsülün yırtıldığını bulmuşlardır. ${ }^{9}$ Özkurt ve ark. tarafından yapılan çalışmada bu oranlar \%65 ve \%31 olarak belirtilmiştir. ${ }^{2}$ Cruz ve ark. ise en sık irrigasyon-aspirasyon sırasında AKR saptamışlardır. ${ }^{5}$ Bizim çalışmamızda AKR; grup 1'de en sık fakoemülsifikasyon aşamasında gelişirken, grup 2'de irrigasyon-aspirasyon aşamasında meydana gelmiştir. Grup 1'de AKR’nin en sık olarak fakoemülsifikasyon aşamasında meydana gelmiş olmasının sebebi, bu grupta matür katarakt oranının daha fazla bulunmasıyla ilişkili olabilir.

Cerrahi sırasında yetersiz dilatasyon cerrahinin her aşamasında zorluklara sebep olduğu için komplikasyon açısından risk faktörüdür. Dada ve arkadaşlarının yaptığı bir çalışmada fakoemülsifikasyon cerrahisinden ekstrakapsüler katarakt cerrahisine dönülmesinin en sık sebebi olarak intraoperatif miyozis gösterilmiştir. ${ }^{10}$ Çalışmamızda her iki grup arasında pupilla dilatasyonu açısından anlamlı farklılık saptanmamıștır.

Sistemik hipertansiyon varlığı ile komplikasyon oranında artış olduğuna dair net bir sonuca varılamamıştır. Lumme ve arkadaşları ${ }^{11}$, Küchle ve arkadaşlarının ${ }^{12}$ yaptıkları çalışmalarda herhangi bir bağlantı bulunmamışken, Abbasoğlu ve arkadaşlarının çalışmasında AKR'ne bağlı vitreus kaybı sistemik hipertansiyonu olanlarda 1,7 kat fazla bu- lunmuştur. ${ }^{13}$ Diyabetes mellitus varlığı ise farklı mekanizmalarla AKR'yi indirekt olarak etkilemektedir. Diyabetik hastalarda rigid pupilla varlığı veya geçirilmiş pars plana vitrektomi öyküsü cerrahiyi komplike hale getirebilmektedir 6. Liu ve arkadaşlarının yaptığ 65370 hastanın incelendiği bir çalışmada diyabeti olmayıp katarakt ameliyatı geçiren hastaların postoperatif görme düzeyleri; diyabeti olup retinopatisi olmayan hastalara göre daha iyi bulunmuştur. Diyabetik retinopatinin şiddeti arttıkça preoperatif ve postoperatif görme düzeyleri anlamlı olarak daha düşük bulunmuştur. ${ }^{14}$ Çalışmamızda iki grup arasında diyabetik ve hipertansif hasta sayısı açısından farklılık yoktu.

Ionides ve ark.'nın yaptığı çalışmada preoperatif ek oküler hastalığı olan olgulara bakıldığında AKR gelişen olgularda kötü görsel sonuç oranı fazla bulunmuştur. ${ }^{15}$ Narendran ve ark.; artmış yaş, erkek cinsiyet, glokom ve DRP varlığı, beyaz katarakt varlığı, kornea opasitesi, psödoeksfoliasyon ve fakodonezis varlığı ve küçük pupil çapını intraoperatif AKR için risk faktörü olarak belirtmişlerdir. ${ }^{16}$

Çalışmamızda Grup 1' de korneal, retinal ve glokomatöz ek oküler patolojilerin varlığ ${ }_{1}$ anlamlı olarak yüksek bulunmuştur. AKR gelişimine rağmen, operasyonun uygun bir şekilde tamamlandığı ve İOL implantasyonunun yapılabildiği olgularda oküler ek patolojisi yoksa iyi bir görme seviyesine ulaşılabilmektedir. Grup 1'de matür katarakt oran1, Grup 2'den fazla bulunmuştur. Bu durum Grup 1'deki kataraktların sert olduğunu göstermektedir. Kataraktın sertliği arttıkça komplikasyon gelişme oranı artmakta ve postoperatif görme düzeyi daha düşük olabilmektedir. Grup 1'de sekonder İOL implantasyon oran1, Grup 2'den yüksek bulunmuştur. Hastalara ilk seansta İOL konulamayıp sekonder olarak İOL implantasyonu yapılmasi; postoperatif kornea ödemi, kistoid makula ödemi, İOL desantralizasyonu gibi komplikasyonların fazla olmas1 sebebiyle sonuç görme keskinliğini düşürebilir.

Grup 1'de nükleus drop oranı istatistiksel olarak anlamlı olmamakla birlikte Grup 2'den fazla bulunmuştur. Cerrahi 
sırasında vitreus kaybı ve drop olan olgularda gerek vitrektomi ihtiyacı olmaları gerek vitreus traksiyonlarına bağlı vitreomaküler ara yüzey hasarından dolayı postoperatif görme düzeyleri komplikasyon gelişmemiş olgulara göre daha düşük olabilir.

Çalışmaya alınan hasta sayısının az olması ve kontrol grubunun olmaması çalışmanın kısıtllılıları olarak düşünülebilir.

Sonuç olarak; fakoemülsifikasyon cerrahisi sırasında AKR gelişen hastalarda; ek oküler hastalığı mevcutsa veya sert kataraktı varsa cerrahi uygun şekilde tamamlansa da ek cerrahiler gerekebilmekte ve bu olgularda görme düzeyi istenen düzeye çıkamamaktadır. Böyle risk faktörü olan olgularda cerrahi planlamanın ona göre yapılarak komplikasyon gelişme oranlarının azaltılması önemlidir. 
Sakarya Tıp Dergisi 2021;11(4):836-842

GÜNDOĞDU ve Ark., Arka Kapsül Rüptürü

\section{References}

1. Kelman CD. Phacoemülsification and aspiration. A new technique of cataract removal. A preliminary report. Am J Ophtalmol 1967; 64:23-35

2. Özkurt Y, Karacan Ö, Oral Y, Arsan A, Oğuz E, Doğan Ö.Fakoemülsifikasyon cerrahisinde oluşan arka kapsül perforasyonu ve zonüler ayrıșmanın değerlendirilmesi. T Oft Gaz. 2003;33:612-616.

3. Gimbel HV. Posterior capsule tears using phacoemulsification-causes, prevention and management. Eur J Implant Refract Surg. 1990;2:63-69.

4. Jaffe N. Cataract Surgery and Its Complications. 3rd ed. St. Louis, MO: Mosby, 1981;368:576-79

5. Cruz OA, Wallace GW, Gay CA, Matoba AY, Koch DD. Visual results and complications of phacoemulsification with intraocular lens implantation performed by ophthalmology residents. Ophthalmology 1992;99:448-452.

6. Zare M, Javadi MA, Einollahi B, Baradaran-Rafii AR, Feizi S, Kiavash V. Risk Factors for Posterior Capsule Rupture and Vitreous Loss during Phacoemulsification. J Ophthalmic Vis Res. 2009;4(4):208-212.

7. Drolsum L, Haaskjold E. The influence of age on characteristics of cataract patients. Acta Ophthalmol (Copenh) 1994;72:622-626.

8. Bai H, Yao L, Wang H. Clinical Investigation into Posterior Capsule Rupture in Phacoemulsification Operations Performed by Surgery Trainees. J Ophthalmol. 2020 Feb 12;2020:1317249. doi: 10.1155/2020/1317249. PMID: 32104591; PMCID: PMC7037484.

9. Karakurt A., Karadağ R., Recep Ö. F., Erdoğan S., Hastripi H. Fakoemülsifikasyon Cerrahisinde Arka Kapsül Yırtılmasina Etkili Risk Faktörleri. Glokom Katarakt, vol.3, pp.165-170, 2008
10. Dada T, Sharma N, Vajpayee RB, Dada VK. Conversion from phacoemulsification to extracpsular cataract extraction: incidence, risk factor, and visual outcome. J Cataract Refract Surg 1998;24:1521-1524.

11. Lumme P, Laatikainen LT. Risk factors for intraoperative and early postoperative complications in extracapsular cataract surgery. Eur J Ophthalmol 1994;4:151-158.

12. Küchle $M$, Schönherr U, Dieckmann U. Risk factors for capsular rupture and vitreous loss in extracapsular cataract extraction. The Erlangen Ophthalmology Group. Fortschr Ophthalmol 1989;86:417-421.

13. Abbasoğlu OE, Hoșal B, Tekeli O, Gürsel E. Risk factors for vitreous loss in cataract surgery. Eur J Ophthalmol 2000;10:227-232

14. Liu L, Herrinton LJ, Alexeeff S, Karter A, Amsden L,Carolan J et al. Visual outcomes after cataract surgery in patients with type 2 diabetes. J Cataract Refract Surg. 2019;45(4):404413. doi:10.1016/j.jcrs.2018.11.002

15. Ionides A, Minassian D, Tuft S. Visual outcome following posterior capsule rupture during cataract surgery. Br J Ophthalmol 2001; 85(2):222-4

16. Narendran N, Jaycock P, Johnston RL, Taylor H, Adams M, Tole DM et al. The Cataract National Dataset electronic multicentre audit of 55,567 operations: risk stratification for posterior capsule rupture and vitreous loss. Eye (Lond) 2009;23(1):31-7 